\title{
Experimental snap loading of synthetic ropes
}

\author{
C.M. Hennessey, N.J. Pearson and R.H. Plaut* \\ The Charles E. Via, Jr. Department of Civil and Environmental Engineering, Virginia Polytechnic Institute and \\ State University, Blacksburg, VA 24061-0105, USA
}

Received 25 February 2004

Revised 22 July 2004

\begin{abstract}
Large tensile forces, known as snap loads, can occur when a slack rope becomes taut. Such forces may damage the rope or masses connected to it. Experiments are described in which one end of a rope is attached to the top of a drop tower and the bottom end is attached to a weight. The weight is raised to a certain height and then released. The force at the top of the rope and the acceleration of the weight are recorded during the first snap load that occurs. Repeated drop tests are performed on each rope. The effects of the type of rope, drop height, drop weight, whether the rope has been subjected to static precycling, and the number of previous dynamic tests are examined. A mathematical model is proposed for the rope force as a function of the displacement and velocity of the weight.
\end{abstract}

\section{Introduction and background}

When a rope or cable is slack and then becomes taut, a large dynamic tension may suddenly build up. This is called a snap load. Snap loading may cause damage or failure to the rope or cable, or to any attached mass. A number of analyses of snap loading have been presented in the literature, but few experimental results have been reported.

Singh [32] considered two satellites connected by an inextensible tether and orbiting the earth. The tether can be alternately slack and "tight," with an inelastic impact assumed to occur when it becomes tight. A similar problem was analyzed by Djerassi and Viderman [8], using the terms "loose" and "taut." The cable can become "instantaneously taut," exerting an impact on the attached bodies, or "continuously taut" with a smooth transition.

Goeller and Laura [12] and Laura and Goeller [19] considered a cable hanging vertically. In their analysis, the cable was divided into segments and the axial force in a segment was constrained to be non-negative. When the force changed from zero to positive in some segments, a large increase in the tension could occur. Liu [23] investigated snap loads induced by surface waves. The cable was modeled using lumped masses, and connecting springs were assigned a zero stiffness if the tension dropped to zero. This use of compressionless springs to model the axial behavior of a cable and the resulting snap loads has appeared in a number of other studies, including Driscoll and Nahon [10], Huang [16], Huang and Vassalos [17,18], Niedzwecki and Thampi [26], Plaut et al. [29], and Wu et al. [38]. A simpler model, assuming that the cable is only in tension instantaneously, was applied by Plaut and Farmer [28] and Plaut et al. [30]. Experiments related to the system in Ref. [29], with a mass suspended by two cables, were described by Virgin et al. [37]. Displacement and velocity data were presented, along with the times at which the cables became momentarily taut.

Brekke and Gardner [6] showed that a tension leg platform can experience large motions associated with the tethers becoming slack at two adjacent corners. However, they claimed that "snap loading" is not very large for this case, since the platform does not acquire large velocities, but they explained how it can be severe in towing when two boats gain a significant relative velocity while the cable is slack. Milgram et al. [24] considered a towing

\footnotetext{
*Corresponding author: Prof. Raymond H. Plaut, The Charles E. Via, Jr., Department of Civil and Environmental Engineering, Virginia Tech, Blacksburg, VA 24061-0105, USA. Tel.: +1 540231 6072; Fax: +1 540231 7532; E-mail: rplaut@vt.edu.
} 


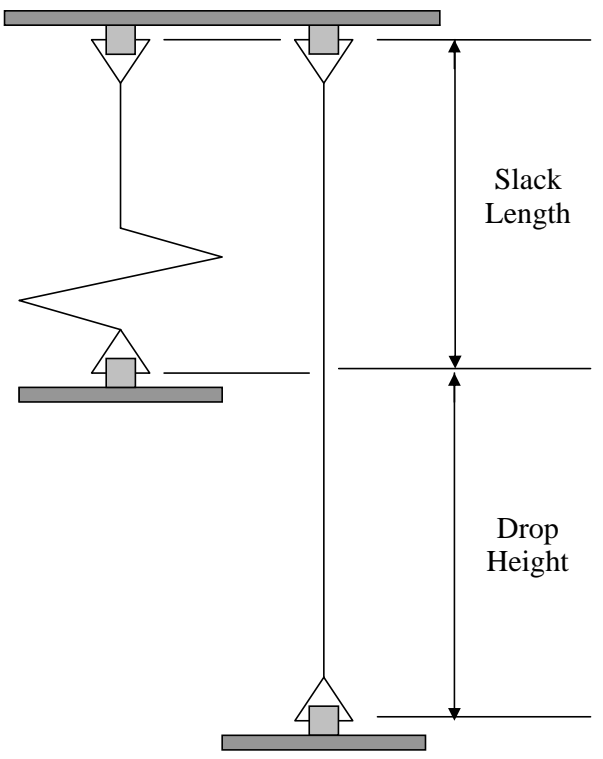

Fig. 1. Schematic of slack rope and taut rope.

situation and used the term "clipping" when the axial force reduces to zero and remains zero for a while. According to Triantafyllou [35], a sudden recovery of tension in underwater cables can lead to impulsive types of motion. The same type of behavior was described by Adrezin et al. [2] with regard to tension leg platforms. Shin [31] considered snap loads in a horizontal chain, and Aliabadi et al. [3] found snap loads in simulations of mooring forces on floating objects.

Driscoll and Biggins [9] studied a vertical cable hanging from a ship, and stated that a rapid re-tensioning of a slack cable can produce dynamic loads several orders of magnitude higher than the normal loads. Choi and Lou [7] investigated the nonlinear dynamic behavior of a periodically slackening mooring line attached to a tanker. Snap loads during upward motion of a mooring chain partially lying on the seabed were examined experimentally and numerically by Gobat and Grosenbaugh [11], while snap loading of multiple cables holding an object (e.g., a diving bell) below a ship were studied by Hann [14]. Vassalos and Huang [36] analyzed the slack/taut behavior of a cable with small sag and with one end displaced harmonically, and Bezverkhii [5] and Tjavaras et al. [34] demonstrated how waves acting on buoys can cause slackening of the anchor line and then a snap load when subsequent tensioning occurs.

Snap loads in static lines involved in parachute deployment by the military were obtained experimentally by Abrate et al. [1] and Millette et al. [25] using drop tests at the US Army Soldier Systems Center in Natick, Massachusetts. Two types of these nylon-webbing restraint straps were tested dynamically, Absorb-Edge ${ }^{\circledR}$ and MIL-W-4088 Type VIII. The straps were $2.4 \mathrm{~m}$ long in Ref. [1] and 2.4-6.1 $\mathrm{m}$ long in Ref. [25]. One end was attached to the top of a tower, and a weight $(1.1-1.8 \mathrm{kN})$ attached to the other end was dropped from increasing heights $(1.1-7.6 \mathrm{~m})$ until rupture occurred. The force at the top of the strap was measured during the drop test (the maximum force was $20 \mathrm{kN}$ ). Then the acceleration of the weight was determined from the force, assuming that stress waves did not affect the force along the strap, and integration yielded the velocity and displacement of the weight. Nonlinear curves of force versus displacement were obtained, and the area inside these hysteresis loops gave the energy absorbed by the strap. When these drop-test curves were compared with similar curves obtained under quasi-static conditions, the loading portions were similar for the Absorb-Edge ${ }^{\circledR}$ straps but different for the Type VIII straps. Approximate formulas for the loading portions of the dynamic curves were presented for the first and second snap loads.

Here, results of drop tests on two types of synthetic ropes are presented. Various drop heights and weights are used, but not sufficient to cause rupture. The experimental setup is described in Section 2. In addition to measuring the force at the top end of the rope, the acceleration at the bottom end is recorded and then integrated to obtain the velocity and displacement there. Static tests used to precycle some of the ropes are discussed in Section 3, and 


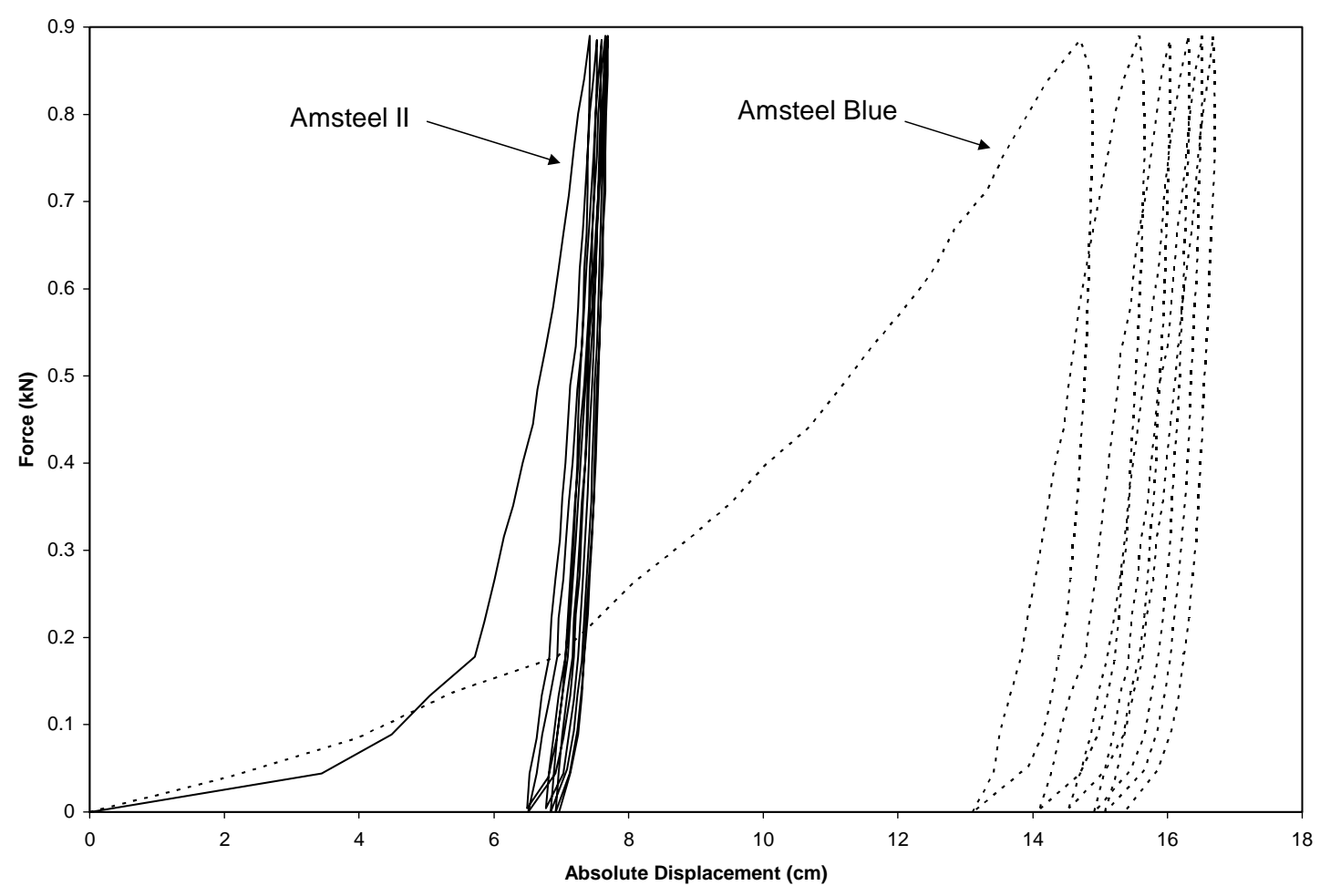

Fig. 2. Six cycles of static force versus elongation for Amsteel II and Amsteel Blue ropes.

typical results of the dynamic tests are given in Section 4. In Section 5, a mathematical model is proposed for the force in the rope, in terms of the displacement and velocity. Finally, concluding remarks are presented in Section 6.

\section{Experimental setup}

A 3.7-m-high drop tower was constructed to conduct the tests [15,27]. It was made of four vertical carbon-steel rods that connect a steel base plate to an aluminum top plate. An aluminum drop plate with dimensions $1.27 \mathrm{~cm}$ by $60 \mathrm{~cm}$ by $60 \mathrm{~cm}$ and weight $110 \mathrm{~N}$ was equipped with four ball-bearing blocks and could slide up and down the rods. Weights could be added to the drop plate. The upper end of the rope was attached to the top plate by means of an assembly which contained a 44-kN load cell, manufactured by Sentran, to measure the force in the rope, and the lower end of the rope was attached to the center of the top of the drop plate. A schematic is shown in Fig. 1, depicting the rope in its initial slack position and then in its straight configuration when it becomes taut.

An accelerometer manufactured by Analog Devices was bolted to the drop plate. Some static tests also were conducted, and for those the displacements of the drop plate were recorded using a cable extension transducer manufactured by Celesco. Data from the load cell and the accelerometer were recorded at 2,000 readings per second by a System 6000 instrument manufactured by Vishay Measurements Group.

The synthetic ropes consist of high-modulus fibers that exhibit high ultimate strengths. When loaded, the fibers are able to stretch well beyond their natural length without rupturing, and then nearly return to their original length when unloaded. The ropes are comprised of thousands of individual fibers which are wound into yarns. Numerous yarns are then twisted together to form plied yarns, which are then compiled into rope yarns. Several rope yarns are assembled into strands by twisting, and the strands are twisted or braided to form a rope. When the rope stretches, the strands are able to move somewhat independently of each other. The fibers elongate and the strands may rotate, causing friction which dissipates some of the input energy [4,20,21].

The ropes were obtained from Samson Rope Technologies in Ferndale, Washington. The ends of the ropes contained 8-cm-long eye splices [22]. Eleven types of ropes were tested, comprised of different combinations of 


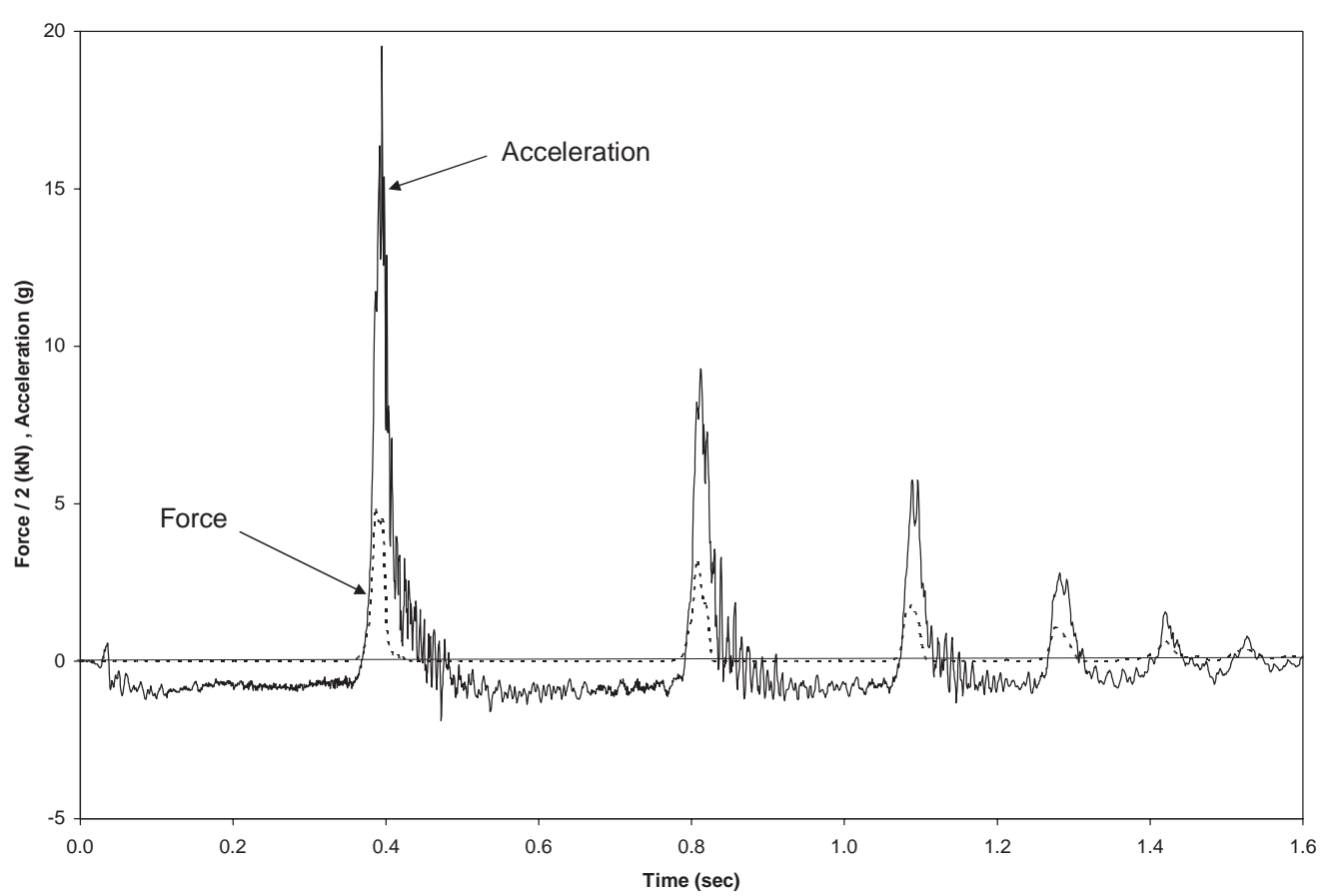

Fig. 3. Dynamic test of Amsteel II rope showing force and acceleration for six taut phases; weight $=289 \mathrm{~N}$, height $=51 \mathrm{~cm}$.

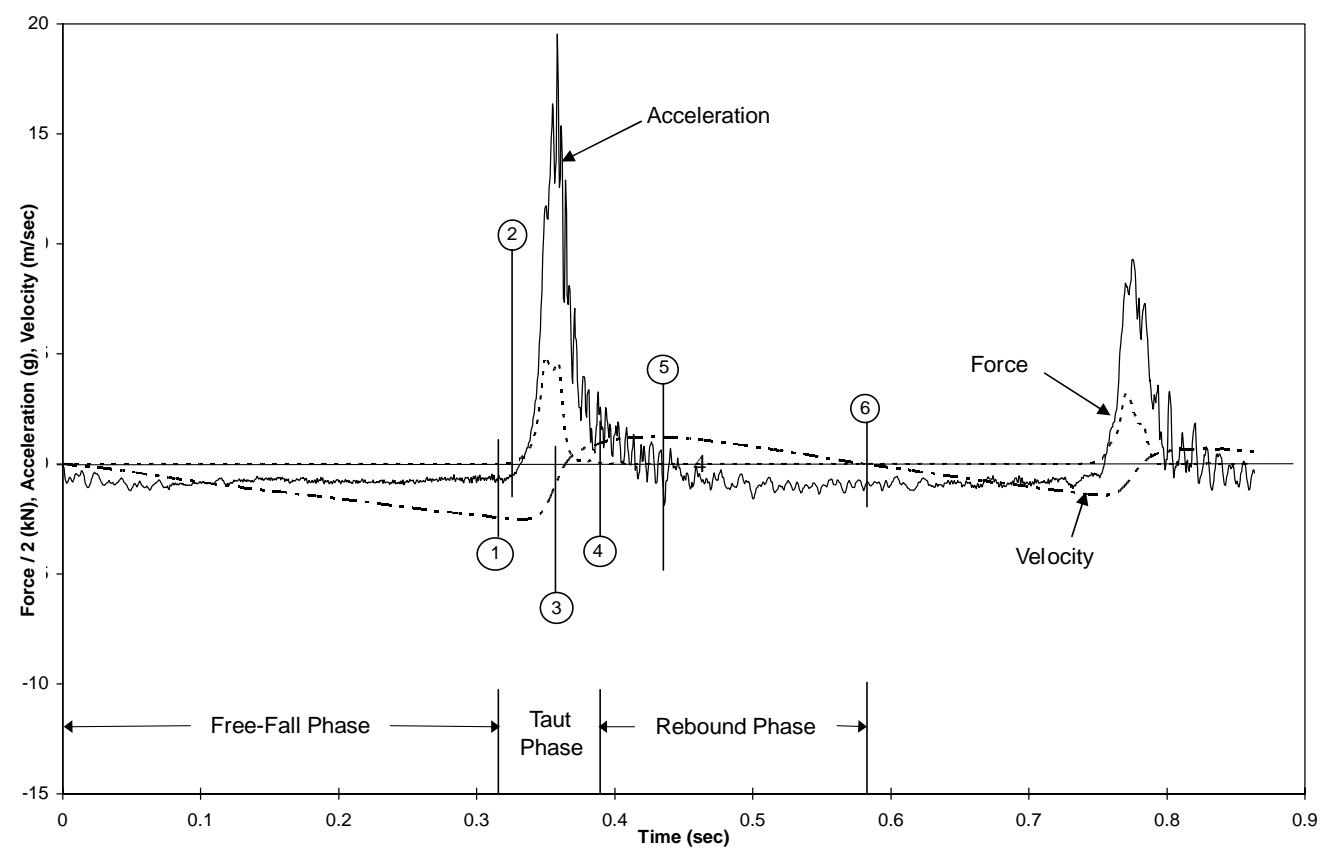

Fig. 4. Same test as in Fig. 3, showing two taut phases; velocity included.

polyester, polypropylene, polyethylene, olefin, Vectran, and Kevlar fibers. The ropes had either single or double braided construction. The rope diameters were either $0.95 \mathrm{~cm}, 1.27 \mathrm{~cm}$, or $1.91 \mathrm{~cm}$, and their initial lengths were either $2.1 \mathrm{~m}$ or $2.7 \mathrm{~m}[15,27]$. Most of the results to be presented will involve two types of ropes, called Amsteel Blue and Amsteel II, with a diameter of $1.27 \mathrm{~cm}$ and an initial length of $2.7 \mathrm{~m}$. The Amsteel Blue ropes, formerly called 


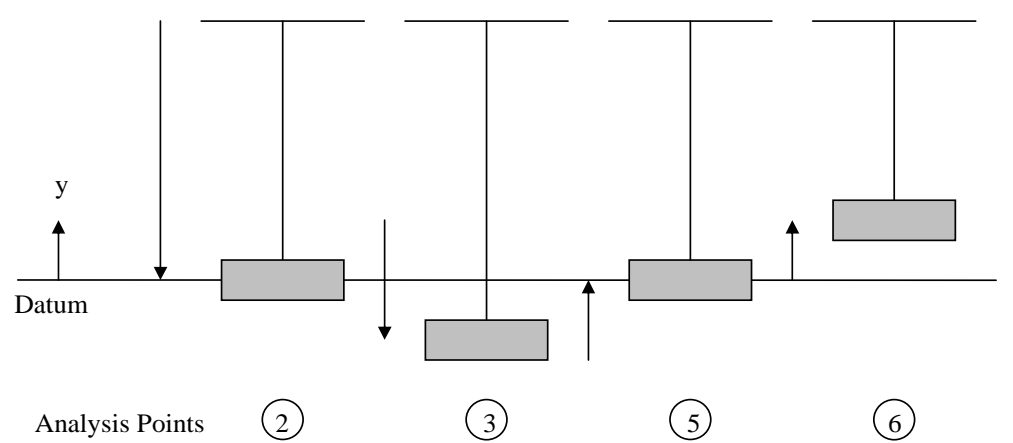

Fig. 5. Schematic of taut phase in dynamic test.

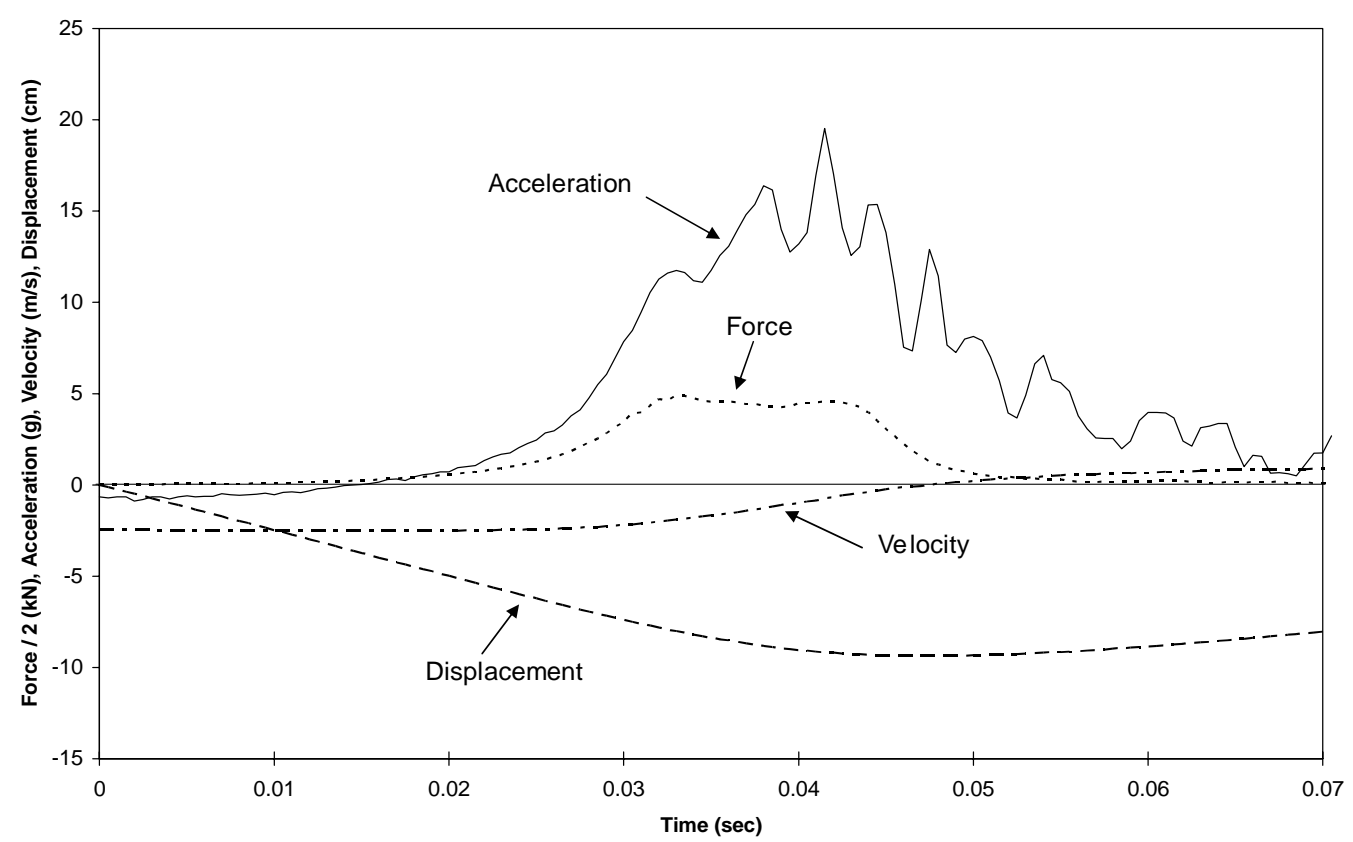

Fig. 6. Same test as in Fig. 4, showing first snap load; displacement included.

Spectron 12 Plus, are made with ultra-high-molecular-weight polyethylene fibers, mainly Dyneema and Spectra, and have the highest strength-to-weight ratio of the 12 types tested. They have excellent resistance to fatigue in flexure. They are loosely braided, very light, and very flexible. The Amsteel II ropes, formerly known as Spectron II, are double braided. The core is braided with high-molecular-weight polyethylene fibers, while the outer cover has a braided polyester construction. These ropes, with their tight braids, have higher strength and stiffness than the Amsteel Blue ropes.

\section{Static tests}

In the static tests, the rope initially hung vertically under the weight of the drop plate. Twenty 44.5-N weights were slowly added, one at a time, and then slowly removed. This cycle was applied six times. One set of results is depicted in Fig. 2, showing the added weight versus the downward displacement of the bottom of the rope (i.e., the elongation). The first cycle begins from the origin, with the displacement set at zero. Naturally the stiffer rope exhibited less displacement. The behavior was inelastic, and the permanent elongations of the Amsteel II and Amsteel Blue ropes after the six cycles were $7.0 \mathrm{~cm}(2.6 \%)$ and $15.3 \mathrm{~cm}(5.7 \%)$, respectively. 


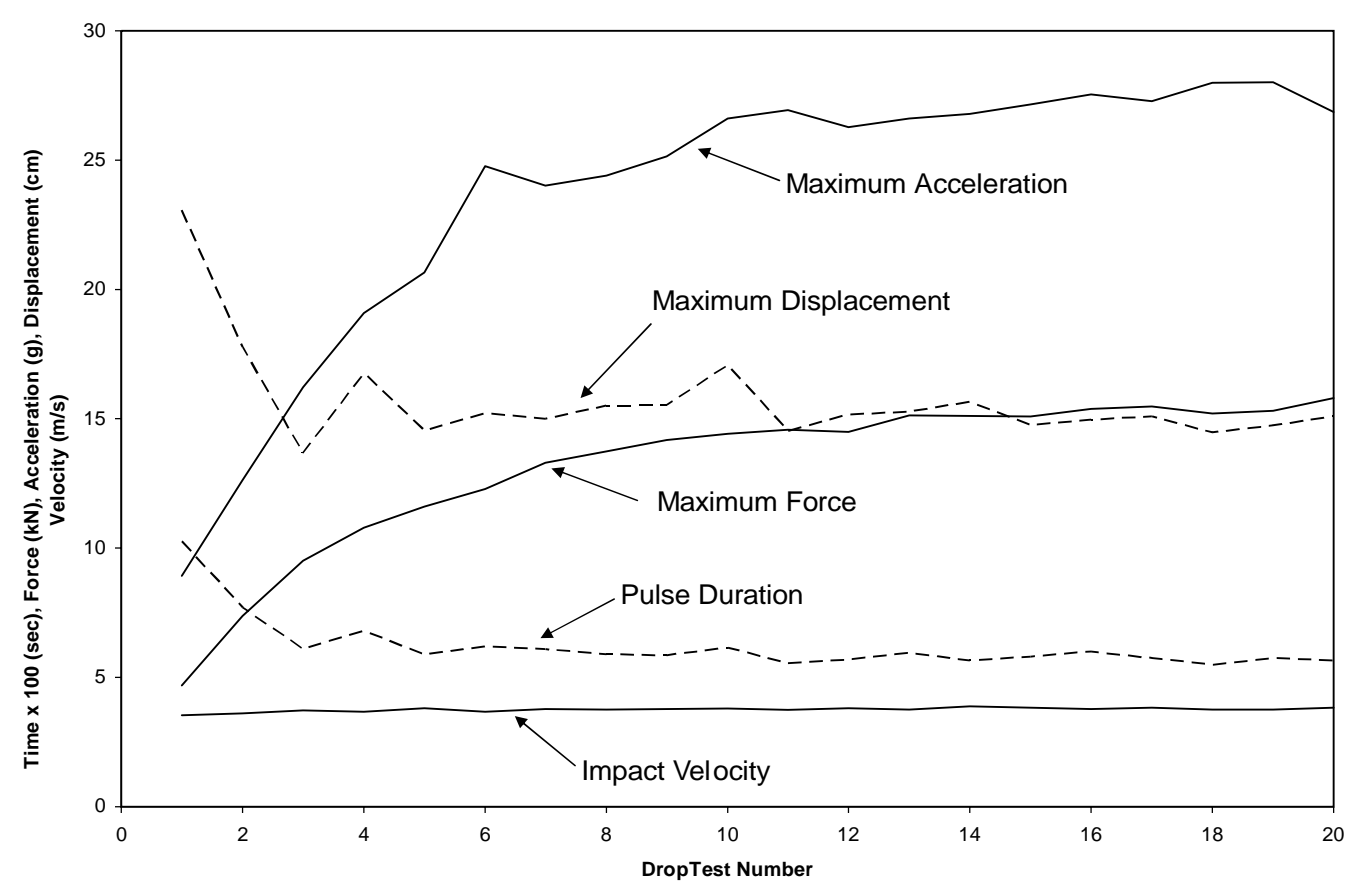

Fig. 7. Sequence of 20 dynamic tests on new Amsteel Blue rope; weight $=289 \mathrm{~N}$, height $=196 \mathrm{~cm}$.

As a new rope is first loaded, it has a low stiffness until the fibers straighten and the strands compress against each other (i.e., the rope constricts). As seen by the increasing slope of the curves emanating from the origin in Fig. 2, the stiffness increases as the load is increased. When the applied weight is reduced, the elongation is only reduced by a small amount. The area of this hysteresis loop is the energy dissipated by friction during this cycle. For subsequent cycles, the slopes of the loading portions of the force-displacement curves are higher than for the first cycle and do not change very much, and the dissipated energy per cycle is much lower than for the first cycle. Results of other tests are given in Refs. [15,27].

Half of the ten ropes of each type were precycled before being tested dynamically, i.e., these ropes were subjected to six cycles of static loading as just described. In the presentation of the dynamic results, ropes will be designated either as "new" or as "precycled."

\section{Dynamic tests}

\subsection{Time histories}

For the dynamic tests, the total weight of the drop plate plus the added weights will be referred to as the weight. Figure 3 shows results of a dynamic test on a new Amsteel II rope with a weight of $289 \mathrm{~N}$ dropped from a height of $51 \mathrm{~cm}$. Six snap loads are shown. The acceleration of the plate is negative as the plate is initially falling, with a magnitude slightly less than $1 \mathrm{~g}$ due to friction and air resistance. During the first snap load, the acceleration (which is really a deceleration of the downward motion) reaches almost $20 \mathrm{~g}$, and the tensile force at the top of the rope, plotted as a dotted curve, reaches almost $10 \mathrm{kN}$. Naturally the peak accelerations and forces are lower for subsequent snap loads in a drop test.

The first two snap loads are shown again in Fig. 4. The velocity is also plotted in this figure, and is negative when the drop plate is falling. The velocity and displacement are obtained by integrating the acceleration data numerically. During the "free-fall phase," the rope is slack (i.e., the force is essentially zero) and the plate is falling. The "taut phase" designates the short time when the rope is under tension (i.e., during the snap load) and is sometimes called an "impact." The velocity at the beginning of this phase will be called the "impact velocity," and the length of time 


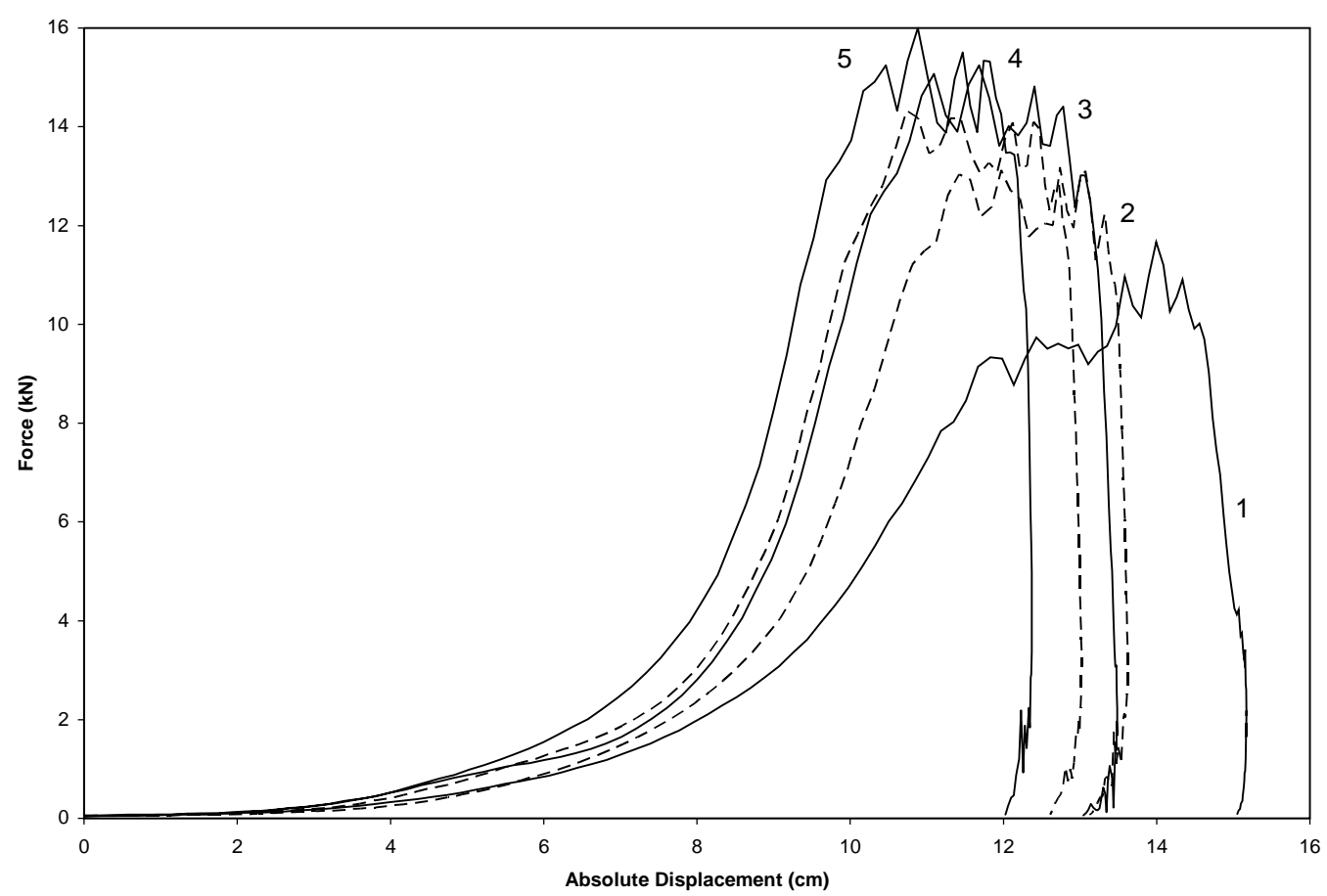

Fig. 8. Force versus elongation for new Amsteel II rope; weight $=289$ N, height $=196 \mathrm{~cm}$.

of the taut phase will be called the "pulse duration." The "rebound phase" refers to the time when the drop plate is rising and the force at the top is essentially zero.

Further results will only involve the first snap load, and the numbers 1, 4, and 6 in Fig. 4 refer to the ends of the three phases for that event. In particular, data will be computed for the points 2, 3, and 5, which are also shown in the schematic in Fig. 5. At point 2, the acceleration is zero, the velocity magnitude is maximum, and the datum point for the vertical displacement $y$ is set. At point 3, the downward displacement is maximum and the velocity is zero. At point 5, the displacement is again at its datum point, and at point 6 the velocity is zero. The loss of energy during the snap load will be computed as the difference in kinetic energy of the weight at points 2 and 5 , which have the same potential energy. The kinetic energy of the rope is neglected.

The results for the first taut phase in the dynamic test shown in Figs 3 and 4 are also plotted in Fig. 6, with the time scale beginning at point 1 . The displacement curve is also plotted. The pulse duration is 0.07 seconds, but the tension has a significant value only for a fraction of this time. The maximum elongation of the rope (to be called the "maximum displacement") is $9.4 \mathrm{~cm}$.

\subsection{Successive tests with same height and same weight}

Figure 2 illustrated how the behavior of a rope under static loading depends on the history of loading. The response of a rope during a dynamic test also depends on previous loading. Figure 7 shows results of a sequence of 20 drop tests on a new Amsteel Blue rope. Each test involved a weight of $289 \mathrm{~N}$ dropped from a height of $196 \mathrm{~cm}$. The curves correspond to quantities during the first taut phase. Except for the impact velocity, the quantities change significantly during a number of successive drop tests and then tend to level off. For this rope, the maximum displacement and the pulse duration exhibit large changes for the first few tests, whereas the maximum acceleration and the maximum force increase substantially during the first 10 tests.

It is interesting to compare curves of force versus downward displacement during the first taut phase in a sequence of dynamic tests. Figure 8 depicts results of the first five tests for a new Amsteel II rope, using the same weight and height as in Fig. 7. The curves are shifted so that the displacement begins from zero for each curve (unlike Fig. 2). Here the maximum force is almost constant after the third drop test. The areas under these curves do not represent the dissipated energy, since the potential energy and kinetic energy of the weight must be taken into account. 


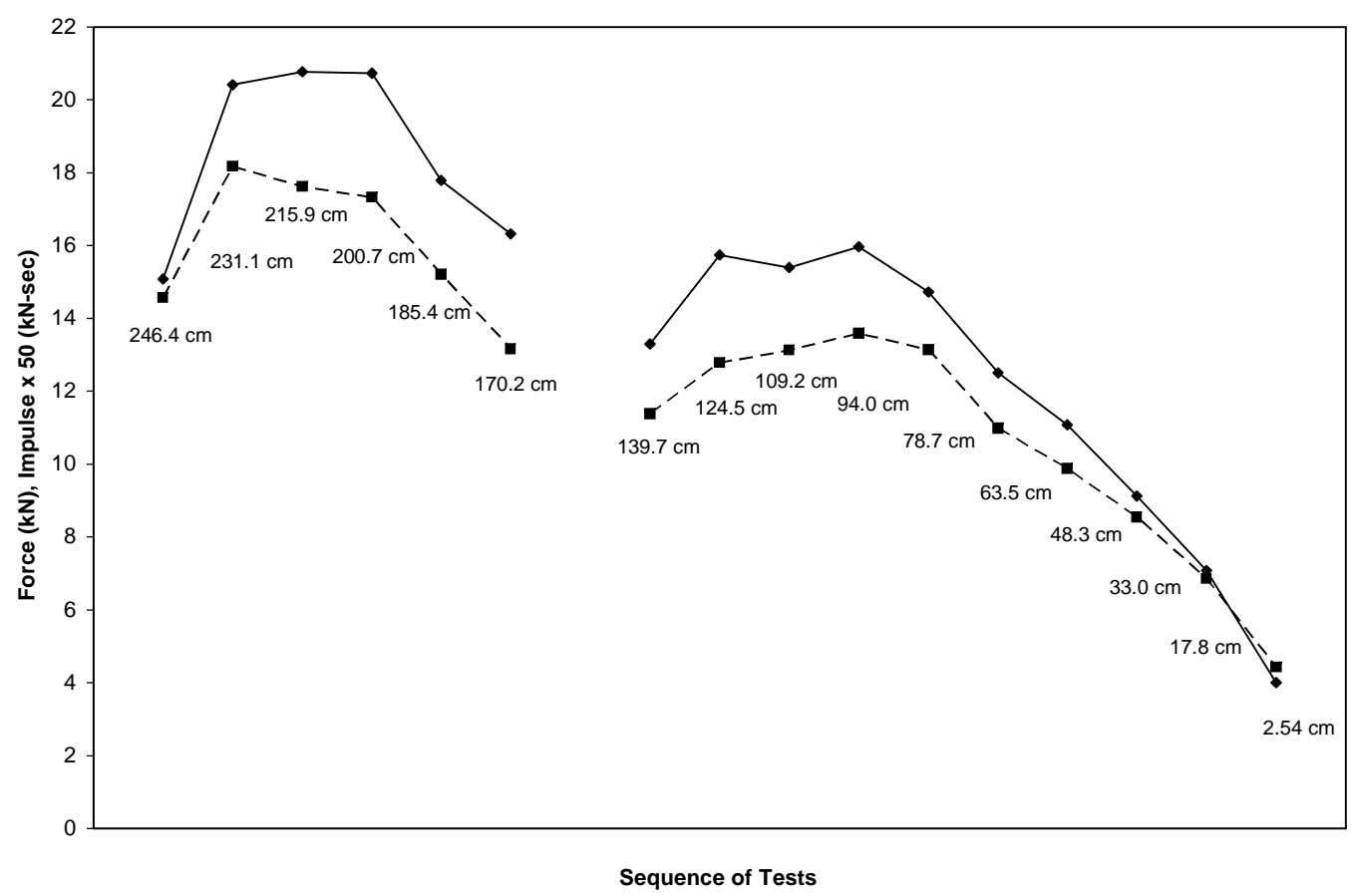

Fig. 9. Two sequences of dynamic tests on precycled Amsteel Blue rope with $0.95 \mathrm{~cm}$ diameter; weight $=289 \mathrm{~N}$, decreasing heights.

\subsection{Successive tests with varying height or weight}

The "impulse" is defined as the area under the curve of force versus time during the first taut phase (e.g., see Fig. 6 for such a curve). It is computed numerically from the recorded data. Successive dynamic tests with varying drop height or weight were conducted, and some results of impulse, maximum force, and dissipated energy were obtained.

In Fig. 9, the weight is held constant and the drop height is changed during a couple of sequences. The weight is $289 \mathrm{~N}$ and each of the two sequences is conducted on a precycled Amsteel Blue rope with a diameter of $0.95 \mathrm{~cm}$. For the first sequence, six tests were conducted with decreasing heights, starting with a height of $246.4 \mathrm{~cm}$ and changing in equal increments till the last height of $170.2 \mathrm{~cm}$. If the rope did not change properties during a sequence, one would expect the impulse and maximum force to decrease monotonically as the drop height decreased. However, these quantities increase initially, implying that the effect of the stiffening of the rope during the first drop tests is more important than the reduction of height. After a few tests in the sequence, the impulse and maximum force are seen to decrease as the height decreases. A similar behavior is demonstrated in the second sequence, which involves 10 tests at lower heights.

Figure 10 illustrates the effect of the drop height on the energy dissipated during the first taut phase. All tests involved a weight of $289 \mathrm{~N}$. Each data point represents the average energy loss over 20 successive dynamic tests from the same height. Results are shown for new and precycled Amsteel Blue ropes with a diameter of $1.27 \mathrm{~cm}$, and new and precycled Amsteel II ropes with a smaller diameter of $0.95 \mathrm{~cm}$. Two data points at the middle height were not obtained for the Amsteel Blue ropes. The trend is clear: the energy loss increases as the drop height increases. The looser Amsteel Blue ropes usually have a higher energy loss when compared to the smaller-diameter Amsteel II ropes in Fig. 10.

The effect of changing weight with a constant drop height is shown in Fig. 11. All three ropes are new and have a length of $2.7 \mathrm{~m}$. The first sequence involves five dynamic tests on an Amsteel Blue rope with a diameter of $0.95 \mathrm{~cm}$. The drop height is $144.8 \mathrm{~cm}$ and the weight is increased from $200 \mathrm{~N}$ to $556 \mathrm{~N}$ in equal increments. The increase in impulse and maximum force is almost linear with the weight. In the second sequence, the rope is called RP Polyester, which also has a loose braid, but the diameter is twice as large. During the sequence, drop tests were carried out with 


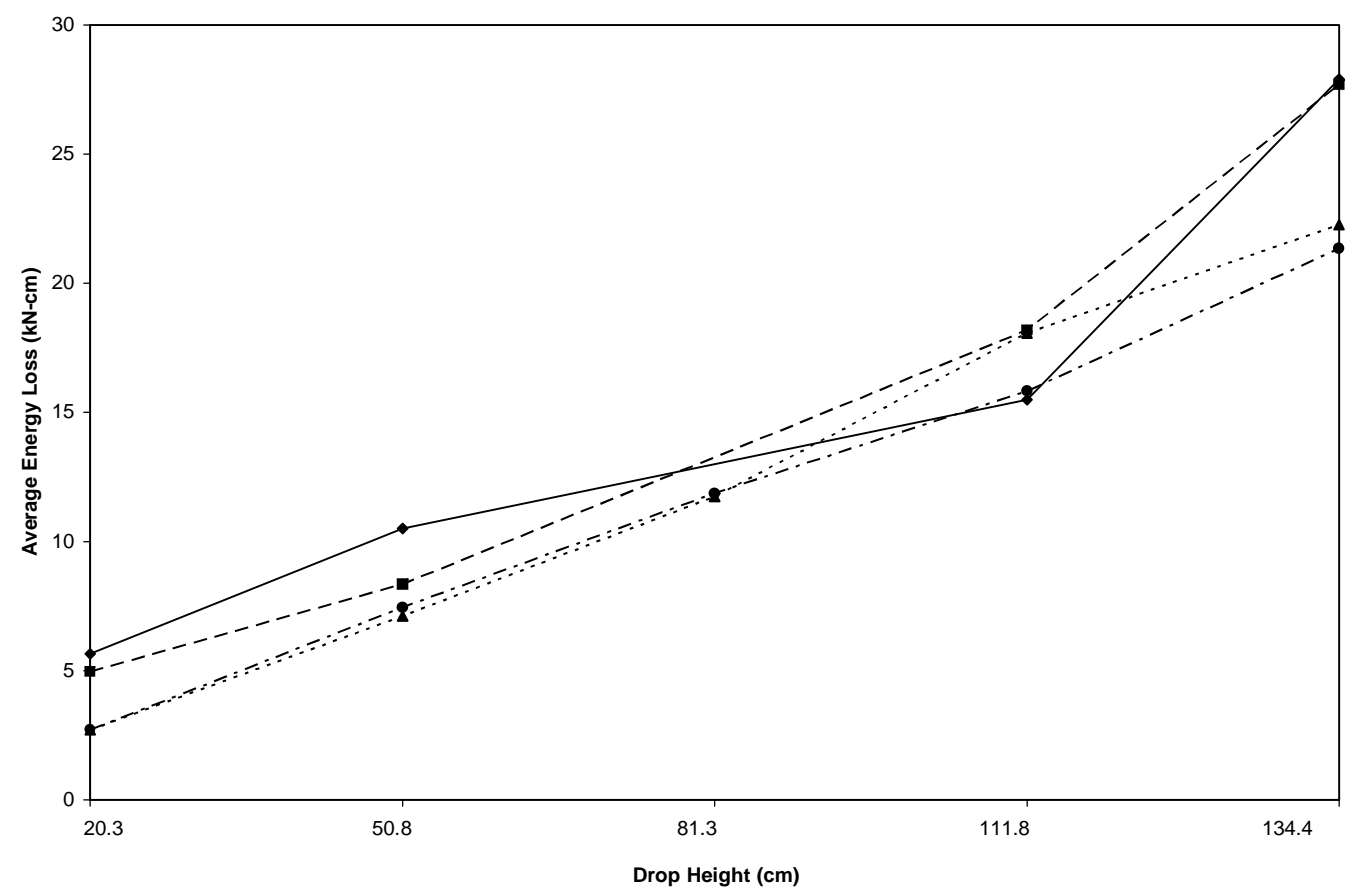

Fig. 10. Effect of height on average dissipated energy during sequence of 20 dynamic tests; solid = precycled Amsteel Blue, 1.27-cm diameter; dashed = new Amsteel Blue, 1.27-cm diameter; dotted = precycled Amsteel II, 0.95-cm diameter; dash-dot = new Amsteel II, 0.95-cm diameter.

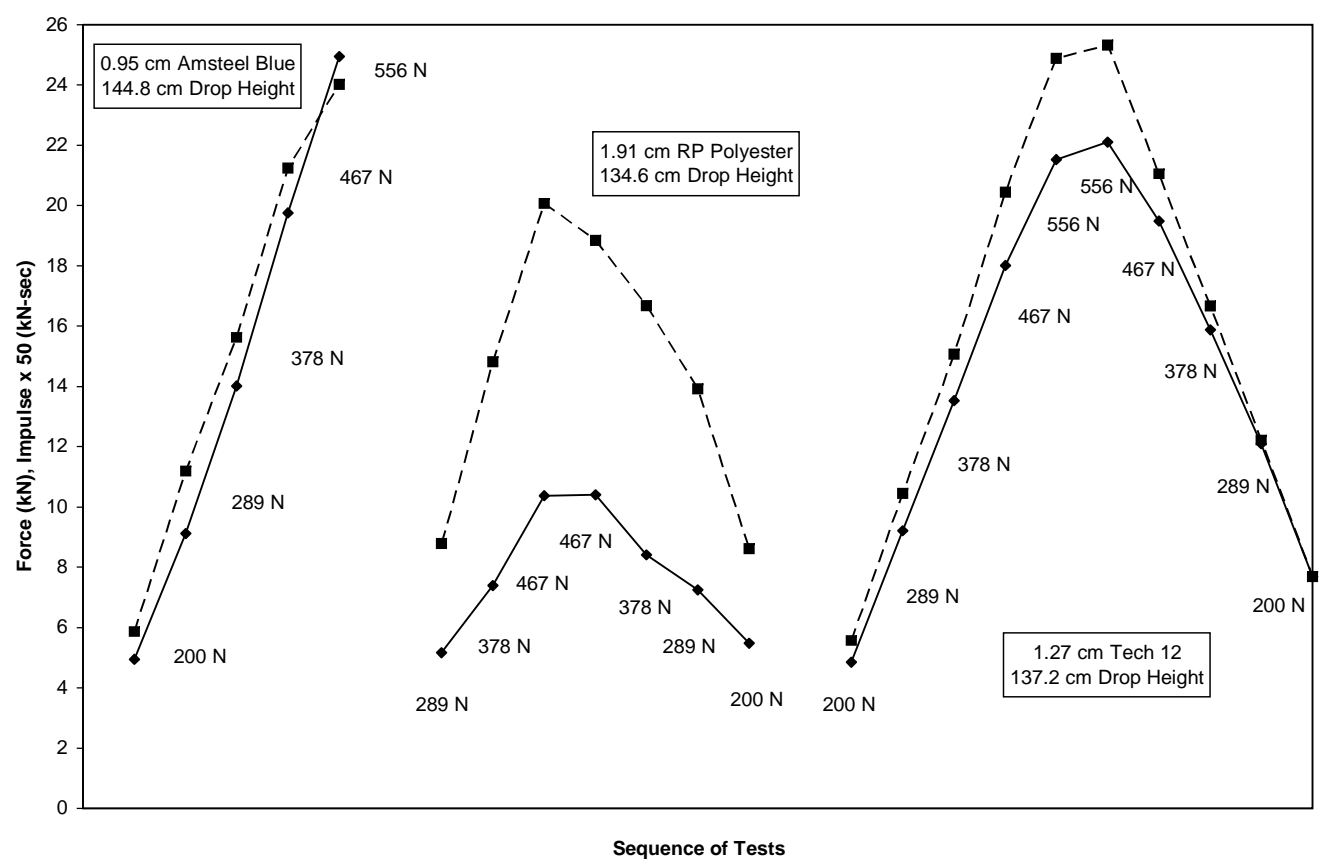

Fig. 11. Three sequences of dynamic tests on new ropes with constant height and varying weight; solid = maximum force; dashed = impulse.

weights of $289 \mathrm{~N}, 378 \mathrm{~N}$, and $467 \mathrm{~N}$. Then another test was conducted with $467 \mathrm{~N}$, followed by tests with decreasing weights of $378 \mathrm{~N}, 289 \mathrm{~N}$, and $200 \mathrm{~N}$. The third sequence involves five tests with increasing weights, and five tests with decreasing weights, for a 1.27-cm-diameter Tech 12 rope which has a tight-braid construction. The curves for 


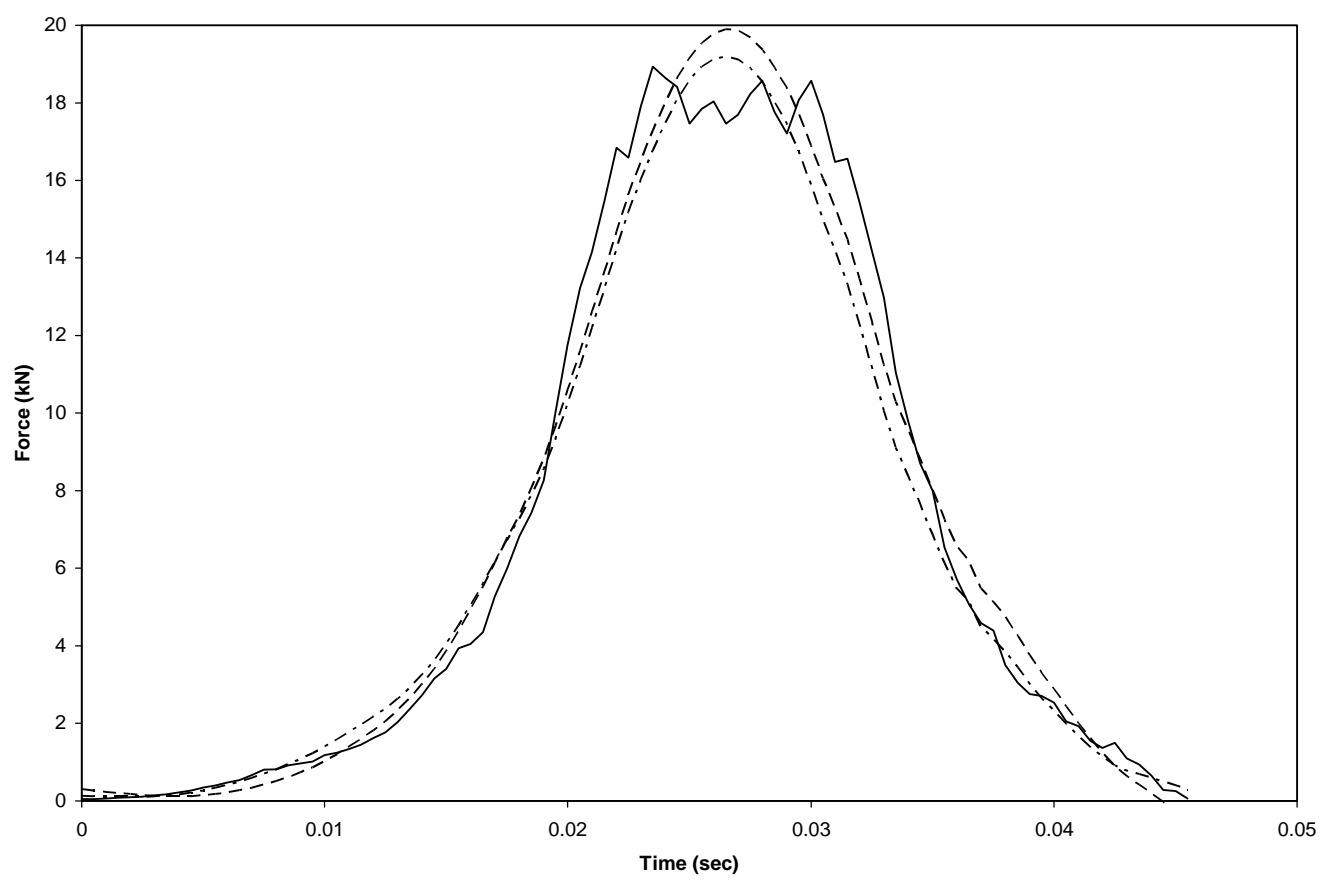

Fig. 12. Force versus time for new Amsteel II rope; weight $=289 \mathrm{~N}$, height $=142 \mathrm{~cm}$; solid $=$ test data; dashed $=$ test equation; dash-dot $=$ sequence equation.

the increasing and decreasing weights are almost linear except for the decreasing curve for the impulse in the second sequence.

\section{Mathematical model for dynamic force}

One objective of this research was the development of a mathematical model that could be used in the dynamic analysis of a structural or mechanical system involving ropes exhibiting snap loads. In finite element analysis, typically the unknown quantities are displacements and velocities at nodes. Therefore, it is desirable to have a formula for the snap load that depends on the relative displacements and velocities at its ends.

An example considered here is the first snap load of a new Amsteel II rope with a diameter of $1.27 \mathrm{~cm}$ and a length of $2.7 \mathrm{~m}$, subjected to a weight of $289 \mathrm{~N}$ dropped from a height of $142 \mathrm{~cm}$. Results of the tenth dynamic test in a sequence of 20 successive tests are shown in Figs 12-14 as force versus time, elongation, and velocity, respectively.

Simple formulas were considered. It was found that a formula including a constant term and uncoupled linear, quadratic, and cubic terms in the displacement and the velocity worked well. That is, the force $F$ in the rope was assumed to have the form

$$
F=a_{0}+a_{1} y+a_{2} v+a_{3} y^{2}+a_{4} v^{2}+a_{5} y^{3}+a_{6} v^{3}
$$

where $y$ and $v$ denote the displacement and velocity, respectively. The coefficients $a_{j}$ were obtained using the triplets $(F, y, v)$ from the experimental data and applying a nonlinear multiple regression analysis in the software package SigmaPlot. Addition of the coupled terms $y v, y^{2} v$, and $y v^{2}$ in Eq. (1) did not significantly improve the accuracy of the approximation [15].

In Figs 12-14, solid curves represent the experimental results. Application of Eq. (1) to the data from this single test yielded the dashed curves, which give a good fit. When the coefficients were based on data from the entire sequence of tests with the rope, the dash-dot curves were obtained. The accuracy of this second approximation for an individual test is sometimes fairly good, and depends on the placement of the test in the sequence. Tables of values of the coefficients in Eq. (1) can be found in Hennessey [15]. 


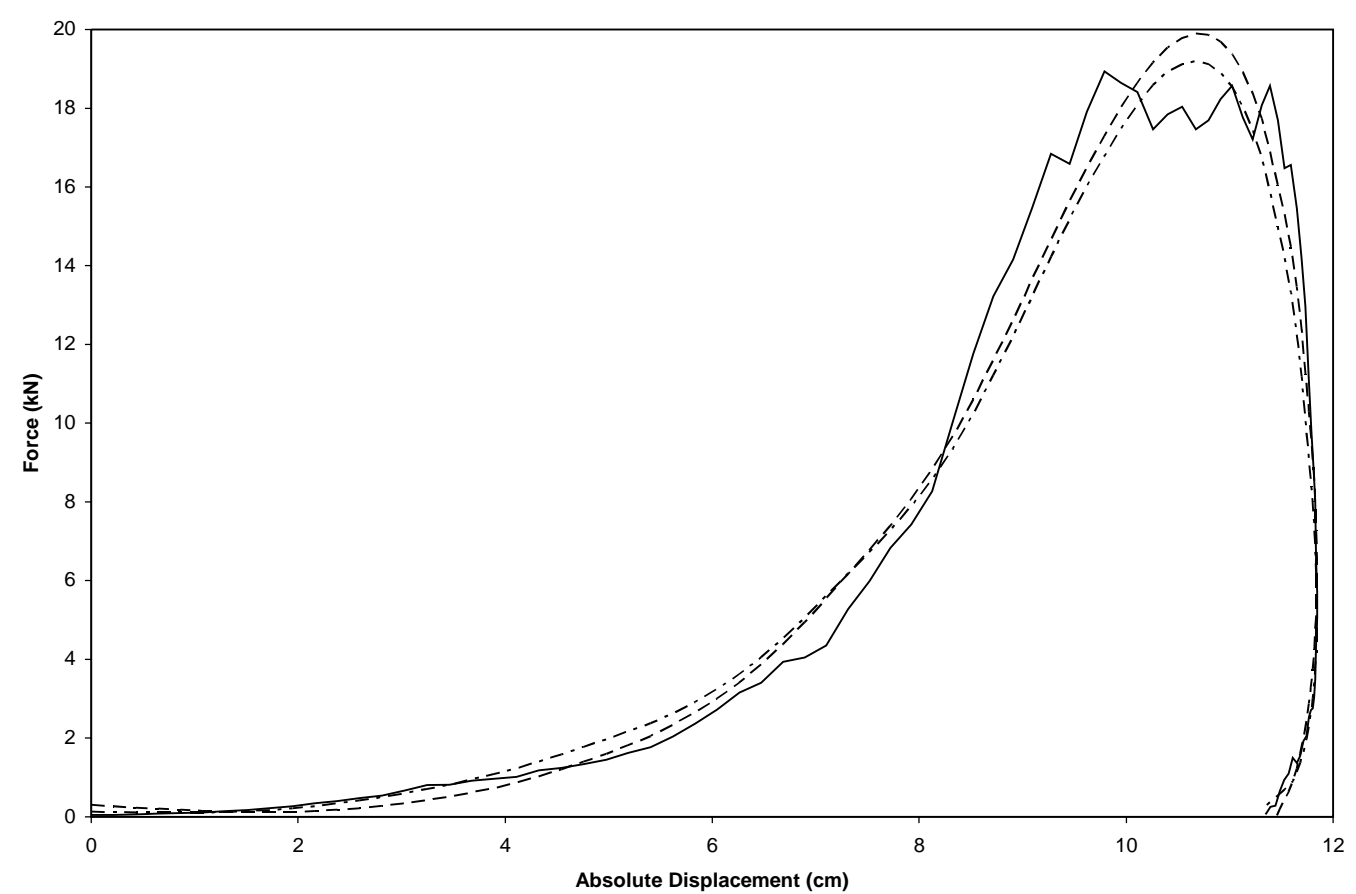

Fig. 13. Force versus displacement for rope in Fig. 12.

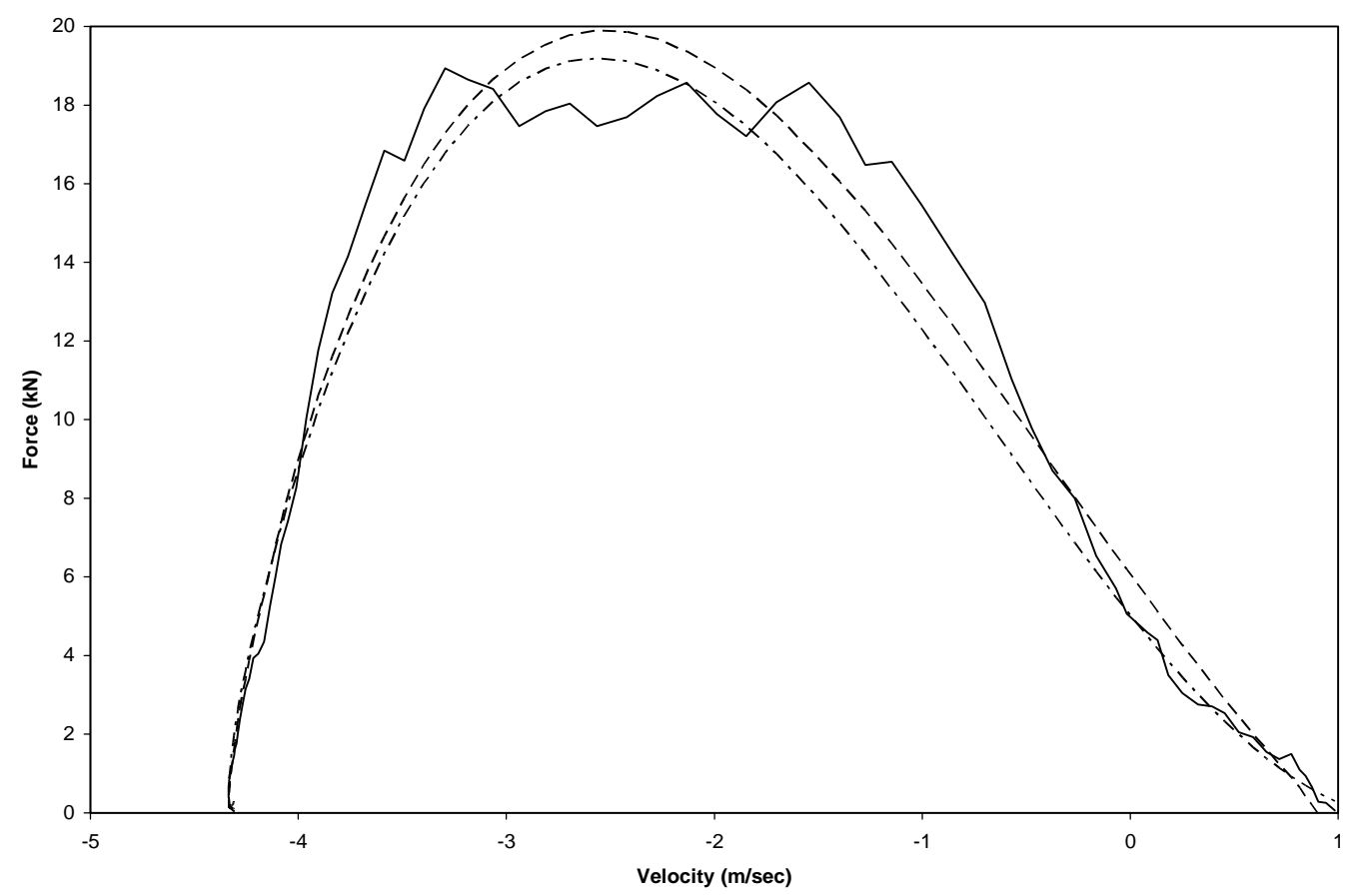

Fig. 14. Force versus velocity for rope in Fig. 12.

\section{Concluding remarks}

This paper has presented some typical results from a research program involving static and dynamic tests of synthetic ropes [15,27]. In the program, 11 types of ropes were tested. Most of the ropes were $2.7 \mathrm{~m}$ long, with a 
diameter of either $0.95 \mathrm{~cm}, 1.27 \mathrm{~cm}$, or $1.91 \mathrm{~cm}$. In the static tests, 28 ropes were used and more than 140 cycles were applied in total, with the additional load to the $110-\mathrm{N}$ plate increased up to $890 \mathrm{~N}$ and then decreased to zero in each cycle. Over 50 ropes were tested dynamically, with a total of more than 700 drop tests conducted. The drop height ranged from $2.5 \mathrm{~cm}$ to $250 \mathrm{~cm}$, and the weight ranged from $110 \mathrm{~N}$ to $645 \mathrm{~N}$. Half of the ropes tested dynamically were precycled with six static cycles, and the others were new ropes.

Most of the results presented in this paper involve a loosely-braided type of rope (Amsteel Blue) or a rope with a double-braided tight construction (Amsteel II). Ropes with looser braiding tended to have more elongation under given static or dynamic loading, as did ropes with a larger diameter.

In the dynamic tests, attention was focused on the first impact (e.g., Fig. 6). With successive dynamic tests, the ropes became stiffer (e.g., Fig. 7) and the amount of energy dissipated during the first snap load decreased. The Amsteel Blue ropes experienced more than twice as much elongation as the Amsteel II ropes, and new ropes exhibited about twice as much elongation as precycled ropes of the same type. The curves of the force versus the elongation have similar shapes for the static and dynamic tests (e.g., Figs 2 and 8), but the slope of the curve (a measure of stiffness) as the maximum force is approached is about four times greater for the dynamic test than for the static test on the same type of rope.

For a given drop height, the maximum force in the rope is approximately proportional to the drop weight (e.g., Fig. 11). For a given weight, after the rope has been subjected to a number of dynamic tests, the force and the energy loss vary almost linearly with the drop height (e.g., Figs 9 and 10).

Longitudinal stress waves can significantly increase the force in the rope [13,33]. In these tests, the theoretical time for a longitudinal stress wave to travel the length of the rope was a small fraction of the pulse duration, and the measured force at the top of the rope was typically about twice as large as the product of the mass and acceleration of the drop plate at the bottom of the rope.

An attempt was made to model the snap load mathematically. Several equations were considered to model the force at the top of the rope as a function of the displacement and velocity at the bottom of the rope. For a given test, and for a sequence of tests on a rope, a cubic function with no coupled terms was able to represent the force well (e.g., Figs 12-14). Such a function could be used in a finite element program to represent the effect of a snap load of a rope.

This investigation is relevant to problems in ocean engineering (e.g., mooring, towing, tension leg platforms), hoisting (e.g., cranes, elevators), parachute lines, guy wires (e.g., towers, masts), transmission lines, satellite tethers, restrainers to mitigate wind and seismic response of buildings and bridges, protective barriers, suspension and cable-stayed bridges, and cable-suspended roofs.

\section{Acknowledgements}

This research was supported by the US National Science Foundation under Grant No. CMS-0114709. The authors are grateful to Dr. Rafael Chou of Samson Rope Technologies for assistance in acquiring the ropes, and Dr. Youngjin Park at Virginia Tech for assistance with the regression analysis. They also thank the reviewers for their helpful comments.

\section{References}

[1] S. Abrate, R. Dooley, R. Kaste, G. Thibault and W. Millette, Nonlinear dynamic behavior of parachute static lines, Composite Structures 61(1) (2003), 3-12.

[2] R. Adrezin, P. Bar-Avi and H. Benaroya, Dynamic response of compliant offshore structures - Review, Journal of Aerospace Engineering 9(4) (1996), 114-131.

[3] S. Aliabadi, J. Abedi and B. Zellars, Parallel finite element simulation of mooring forces on floating objects, International Journal for Numerical Methods in Fluids 41(8) (2003), 809-822.

[4] S. Banfield and N. Casey, Evaluation of fibre rope properties for offshore mooring, Ocean Engineering 25(10) (1998), 861-879.

[5] A.I. Bezverkhii, On oscillations of anchored buoys on waves, International Applied Mechanics 34(4) (1998), $398-403$.

[6] J.N. Brekke and T.N. Gardner, Analysis of brief tension loss in TLP tethers, Journal of Offshore Mechanics and Arctic Engineering 110(1) (1988), 43-47. 
[7] H.S. Choi and J.Y.K. Lou, Nonlinear mooring line induced slow drift motion of an ALP-tanker, Ocean Engineering 20(3) (1993), $233-246$.

[8] S. Djerassi and Z. Viderman, Motion analysis of two cable-connected bodies in atmospheric free-fall, Journal of Aircraft 35(1) (1998), 78-83.

[9] R. Driscoll and L. Biggins, Passive damping to attenuate snap loading on a ROV umbilical cable, in: Oceans '93, (Vol. I), IEEE, New York, 1996, p. 409.

[10] R. Driscoll and M. Nahon, Mathematical modeling and simulation of a moored buoy system, in: Oceans '96, (Vol. 1), MTS/IEEE Conference Proceedings, 1996, pp. 517-523.

[11] J.I. Gobat and M.A. Grosenbaugh, Dynamics in the touchdown region of catenary moorings, International Journal of Offshore and Polar Engineering 11(4) (2001), 273-284.

[12] J.E. Goeller and P.A. Laura, Analytical and experimental study of the dynamic response of segmented cable systems, Journal of Sound and Vibration 18(3) (1971), 311-329.

[13] W. Goldsmith, Impact, Dover, Mineola, NY, 2001.

[14] M. Hann, Statics and dynamics of multi-cable systems for submersibles, Marine Structures 8(5) (1995), 555-583.

[15] C.M. Hennessey, Analysis and modeling of snap loads on synthetic fiber ropes, M.S. Thesis, Virginia Polytechnic Institute and State University, 2003, http://scholar.lib.vt.edu/theses/available/etd-11092003-135228/.

[16] S. Huang, Stability analysis of the heave motion of marine cable-body systems, Ocean Engineering 26(6) (1999), 531-546.

[17] S. Huang and D. Vassalos, A numerical method for predicting snap loading of marine cables, Applied Ocean Research 15(4) (1993), $235-242$.

[18] S. Huang and D. Vassalos, Analysis of taut-slack marine cable dynamics, in: OMAE 1995, (Vol. I-B), S.K. Chakrabarti et al., eds, ASME, New York, 1995, pp. 401-406.

[19] P.A. Laura and J.E. Goeller, On the dynamic behavior of a cable system in a recovery operation, Journal of the Acoustical Society of America 49(3) (1971), 615-621.

[20] C.M. Leech, Theory and numerical methods for the modelling of synthetic ropes, Communications in Applied Numerical Methods 3(5) (1987), 407-413.

[21] C.M. Leech, The modelling of friction in polymer fibre ropes, International Journal of Mechanical Sciences 44(3) (2002), 621-643.

[22] C.M. Leech, The modelling and analysis of splices used in synthetic ropes, Proceedings of the Royal Society of London A 459(2035) (2003), 1641-1659.

[23] F.C. Liu, Snap loads in lifting and mooring cable systems induced by surface wave conditions, Technical Note N-1288, Civil Engineering Laboratory, Port Hueneme, CA, 1973.

[24] J.H. Milgram, M.S. Triantafyllou, F. Frimm and G. Anagnostou, Seakeeping and extreme tensions in offshore towing, Transactions of the Society of Naval Architects and Marine Engineers 96(1) (1988), 35-72.

[25] W.L. Millette, Jr., G.W. Thibault, R. Dooley, R. Kaste and P. Mortaloni, Investigation of methods to improve static line effective strength, in: 16th Aerodynamic Decelerator Systems Seminar and Conference, Boston, MA, 2001, Paper AIAA $2001-2023$.

[26] J.M. Niedzwecki and S.K. Thampi, Snap loading of marine cable systems, Applied Ocean Research 13(1) (1991), 2-11.

[27] N.J. Pearson, Experimental snap loading of synthetic fiber ropes, M.S. Thesis, Virginia Polytechnic Institute and State University, 2002, http://scholar.lib.vt.edu/theses/available/etd-01132003-105300/.

[28] R.H. Plaut and A.L. Farmer, Large motions of a moored floating breakwater modeled as an impact oscillator, Nonlinear Dynamics 23(4) (2000), 319-334.

[29] R.H. Plaut, J.C. Archilla and T.W. Mays, Snap loads in mooring lines during large three-dimensional motions of a cylinder, Nonlinear Dynamics 23(3) (2000), 271-284.

[30] R.H. Plaut, A.L. Farmer and M.M. Holland, Bouncing-ball model of dry motions of a tethered buoy, Journal of Vibration and Acoustics 123(3) (2001), 333-339.

[31] H. Shin, Analysis of extreme tensions in a snapping cable, in: Proceedings of the 1st International Offshore and Polar Engineering Conference, (Vol. II), M.S. Triantafyllou et al., eds, ISOPE, Golden, CO, 1991, pp. 216-221.

[32] R.B. Singh, Three-dimensional motion of a system of two cable-connected satellites in orbit, Astronautica Acta 18(5) (1973), 301-308.

[33] S.P. Timoshenko and J.N. Goodier, Theory of Elasticity, 3rd ed., McGraw-Hill, New York, 1970.

[34] A.A. Tjavaras, Q. Zhu, Y. Liu, M.S. Triantafyllou and D.K.P. Yue, The mechanics of highly-extensible cables, Journal of Sound and Vibration 213(4) (1998), 709-737.

[35] M.S. Triantafyllou, Cable mechanics for moored floating systems, in: Behaviour of Offshore Sructures, (Vol. 2), C. Chryssostomidis et al., eds, Elsevier, New York, 1994, pp. 57-78.

[36] D. Vassalos and S. Huang, Dynamics of small-sagged taut-slack marine cables, Computers and Structures 58(3) (1996), 557-562.

[37] L.N. Virgin, J.M. Nichols, W.N. Simmons and R.H. Plaut, On the response of a shaken cable-suspended mass, in: Proceedings of the 18th ASME Biennial Conference on Mechanical Vibration and Noise (DETC'01), Pittsburgh, PA, 2001, Paper DETC2001/VIB-21552.

[38] Q. Wu, K. Takahashi and S. Nakamura, The effect of cable loosening on seismic response of a prestressed concrete cable-stayed bridge, Journal of Sound and Vibration 268(1) (2003), 71-84. 

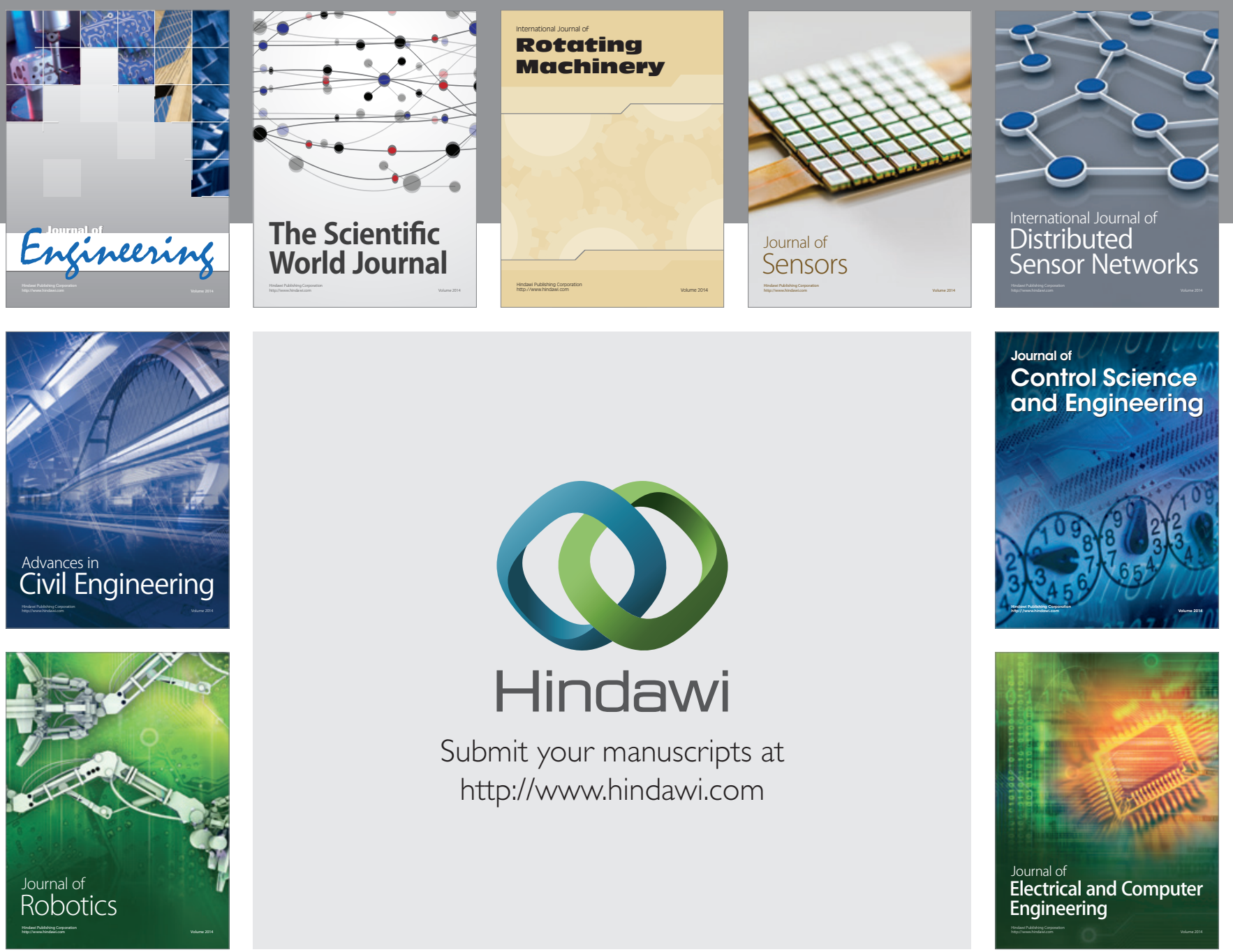

Submit your manuscripts at

http://www.hindawi.com
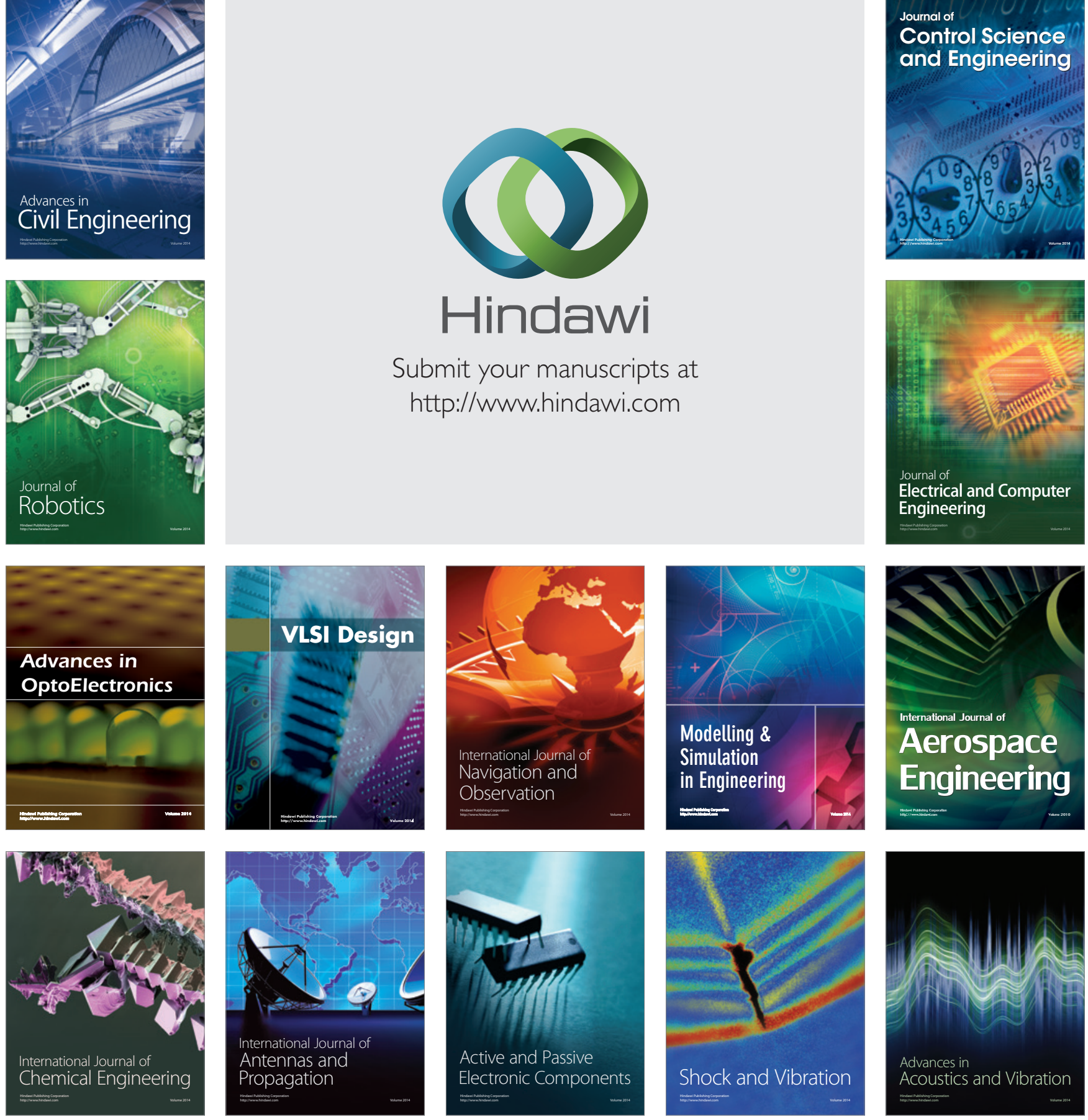